\title{
Soluble versions of outer membrane cytochromes function as exporters for heterologously produced cargo proteins
}

\author{
Helge M. Dietrich ${ }^{1}$, Miriam Edel ${ }^{2}$, Thea Bursac ${ }^{2}$, Manfred Meier ${ }^{3}$, Katrin Sturm-Richter ${ }^{2}$ \\ and Johannes Gescher ${ }^{2,3^{*}}$ (i)
}

\begin{abstract}
This study reveals that it is possible to secrete truncated versions of outer membrane cytochromes into the culture supernatant and that these proteins can provide a basis for the export of heterologously produced proteins. Different soluble and truncated versions of the outer membrane cytochrome MtrF were analyzed for their suitability to be secreted. A protein version with a very short truncation of the $\mathrm{N}$-terminus to remove the recognition sequence for the addition of a lipid anchor is secreted efficiently to the culture supernatant, and moreover this protein could be further truncated by a deletion of 160 amino acid and still is detectable in the supernatant. By coupling a cellulase to this soluble outer membrane cytochrome, the export efficiency was measured by means of relative cellulase activity. We conclude that outer membrane cytochromes of $S$. oneidensis can be applied as transporters for the export of target proteins into the medium using the type II secretion pathway.
\end{abstract}

Keywords: Shewanella oneidensis, Type II secretion system, Outer membrane cytochromes, Protein export, Cellulase, Fusion proteins

\section{Introduction}

Secretion of heterologous proteins into the culture medium is an often-used tool in biotechnology. Typically, this technique is applied in order to reduce the protein purification burden or to engineer cells to thrive on polymeric substrates via the use of excreted hydrolytic enzymes. In general, one has to distinguish between one-step and two-step export machineries. One-step export machineries transport unfolded or partially folded proteins directly from the cytosol to the medium, which requires that the protein has to fold correctly without accessory proteins like foldases or chaperons $[18,28]$. Hence, the production of

*Correspondence: johannes.gescher@kit.edu

${ }^{2}$ Department of Applied Biology, Institute for Applied Biosciences, Karlsruhe Institute of Technology (KIT), Karlsruhe, Germany

Full list of author information is available at the end of the article proteins containing cofactors is a challenge using onestep machineries. In two-step systems, the proteins are first transported across the cytoplasmic membrane via the Sec- or TAT-machinery, which allows the addition of complex co-factors and access to a machinery of proteins that aid in folding [23]. After maturation, the proteins are transported across the outer membrane by a specific secretion apparatus, the so called secretin $[17,32]$. Consequently, secretion across the outer membrane is the more challenging step compared to the translocation into the periplasm. Besides these canonical one-step and two-step machineries other ways to establish transport into the culture supernatant were achieved as well. During industrial production of secreted target proteins, one commonly applied strategy is to destabilize the outer membrane by the addition of detergents which will improve the export but will also lead to a contamination with other periplasmic 
proteins [22]. It was also discovered that special proteins like for example YebF in E. coli are secreted across the outer membrane via an unknown mechanism and that a fusion to these proteins could allow the co-transport of cargo proteins [41].

Probably the best understood two-step pathway to transport folded proteins across the outer membrane is the type II secretion system (T2SS) [35]. It does not only transport mature proteins but the specific fold of the target-protein is recognized by the system and selects for transport [30]. This renders the system hard to use, as an essential recognition structure that enables interaction and transport with the T2SS has not been discovered so far and seems to differ even between closely related strains.

Besides the recognition of target proteins, secretion across the outer membrane necessitates a specific secretion apparatus [17, 32]. It consists of three major parts: an inner membrane subcomplex, several periplasmic pseudopilins and the outer membrane secretin. Interaction of all three components is necessary to enable secretion of proteins through a pore consisting of secretin protein subunits. A lipoprotein named pilotin is a facilitator protein that allows for the assembly of the secretin in the outer membrane. If pilotin is absent, the secretion system cannot operate and the secretin is degraded or mislocalized [21,38].

Some microorganisms completely rely on the T2SS in order to thrive under certain conditions. One of these organisms is the $\gamma$-proteobacterium Shewanella oneidensis MR-1, which uses the T2SS for the export of outer membrane cytochromes to the cell surface [15]. These cytochromes contain multiple heme sites and are lipoproteins that form a trimeric protein complex with a $\beta$-barrel protein and a periplasmic decaheme cytochrome $[13,14]$. This porin-cytochrome complex builds an electron conduit that allows the export of respiratory electrons through the outer membrane and onto insoluble electron acceptors like ferric iron or manganese oxides $[5,34]$. Moreover, this extended respiratory chain is also used in biotechnological applications, as it can catalyze electron transport to and from electrodes [4, 7]. Regarding the outer membrane cytochromes it was speculated by Myers et al. that deletion of the lipid anchor leads to secretion of the proteins into the supernatant [27]. However, this was not experimentally documented yet and moreover it is not known what part of the proteins is recognized by the T2SS.

In this study we demonstrate the secretion of truncated versions of outer membrane cytochromes and asked whether protein fusions facilitate the export of heterologously expressed target proteins into the medium. For the proof of principle, we fused outer membrane cytochromes with a cellulase and measured the cellulase activity in the culture supernatant.

\section{Experimental procedures \\ Growth conditions and media}

Escherichia coli DH5 $\alpha$ ZI served as cloning host and was grown aerobically in $\mathrm{LB}$ medium at $37^{\circ} \mathrm{C} ; \mathrm{S}$. oneidensis strains were cultivated at $30{ }^{\circ} \mathrm{C}$ either aerobically in LB or anaerobically in M4 minimal medium (1.27 mM $\mathrm{K}_{2} \mathrm{HPO}_{4}, 0.73 \mathrm{mM} \mathrm{KH} \mathrm{PO}_{4}, 5 \mathrm{mM}$ HEPES, $2 \mathrm{mM}$ $\mathrm{NaHCO}_{3}, 9 \mathrm{mM}\left(\mathrm{NH}_{4}\right)_{2} \mathrm{SO}_{4}, 150 \mathrm{mM} \mathrm{NaCl}, 3.2 \mathrm{mM}$ Casamino Acids, $0.1 \mathrm{mM} \mathrm{CaCl}, 1 \mathrm{mM} \mathrm{MgSO}_{4}$ ) supplemented with trace elements $\left(5 \mu \mathrm{M} \mathrm{CoCl}_{2}, 0.2 \mu \mathrm{M} \mathrm{CuSO}_{4}\right.$, $5.4 \mu \mathrm{M} \mathrm{FeCl}_{2}, 57 \mu \mathrm{M} \mathrm{H}_{3} \mathrm{BO}_{3}, 1.3 \mu \mathrm{M} \mathrm{MnSO}_{4}, 67.6 \mu \mathrm{M}$ $\mathrm{Na}_{2}$ EDTA, $3.9 \mu \mathrm{M} \mathrm{Na} \mathrm{NoO}_{4}, 1.5 \mu \mathrm{M} \mathrm{Na} \mathrm{SO}_{4}, 5 \mu \mathrm{M}$ $\left.\mathrm{NiCl}_{2}, 1 \mu \mathrm{M} \mathrm{ZnSO}{ }_{4}\right) .50 \mathrm{mM}$ lactate served as electron donor and $50 \mathrm{mM}$ fumarate as electron acceptor. Liquid pre-cultures were cultivated oxically in LB medium at $30{ }^{\circ} \mathrm{C}$ (S. oneidensis) or $37{ }^{\circ} \mathrm{C}$ (E. coli) and $140 \mathrm{rpm}$ in test tubes ( $5 \mathrm{ml}$ medium volume). When necessary, kanamycin $\left(50 \mu \mathrm{g} \mathrm{ml}^{-1}\right)$ and arabinose $(200 \mu \mathrm{M})$ were added to the medium.

For better cytochrome maturation and secretion, all secretion experiments were conducted under anoxic conditions. M4 medium was transferred into medium bottles (100 ml medium in $250 \mathrm{ml}$ Schott flasks) or Hungate tubes ( $10 \mathrm{ml}$ medium in $25 \mathrm{ml}$ tube), respectively and the vessels were sealed with rubber stoppers. Oxygen was removed from the medium by repeatedly flushing the headspace of each bottle for 2 min with nitrogen, followed by a 2 min application of vacuum. Nitrogen gas and vacuum cycles were repeated 25 times before bottles were autoclaved. The electron donor was sterile-filtered with $0.2 \mu \mathrm{m}$ sterile filters and added to the medium after autoclaving. After inoculation, the vessels were incubated statically at $30^{\circ} \mathrm{C}$.

\section{Cloning of different plasmids}

The genotypes of all plasmids that were constructed in this study are listed in Table 1; all primers used for cloning are listed in Additional file 1: Table S1. In general, plasmid pBAD202 (Invitrogen, USA) served as expression vector and was linearized with $\mathrm{NcoI}$ and PmeI. For DNA ligations, equimolar amounts of linearized plasmid and PCR fragment with a total amount of 100 ng DNA were combined and ligation was performed using an isothermal assembly method described by Gibson et al. [19].

\section{Generation of soluble variants of MtrF and OmcA}

In order to achieve soluble versions of MtrF and OmcA, the respective shortened DNA sequence lacking the lipid anchor was amplified from the $S$. oneidensis genome using primers 1 and 2 or primers 3 and 4, respectively. 
Table 1 Microbial strains used in this study

\begin{tabular}{|c|c|c|}
\hline Strain name & Relevant genotype on pBAD plasmid & Reference or source \\
\hline E. coli DH5aZl & $\begin{array}{l}\text { aci q, PN25-tetR, SpR, deoR, supE44, } \triangle(\text { lacZYAargFV169), Phi80 } \\
\text { lacZDM15 }\end{array}$ & [25] \\
\hline Wild type & & Myers and Nealson [26] \\
\hline $\mathrm{OmcA}_{\text {sol }}$ & $\mathrm{Kan}^{\mathrm{R}}, \mathrm{P}_{\mathrm{Ara}}, \mathrm{OmcA}_{\mathrm{sol}}$ & This study \\
\hline $\mathrm{MtrF}_{\mathrm{sol}}$ & $\mathrm{Kan}^{\mathrm{R}}, \mathrm{P}_{\text {Ara }}, m t r \mathrm{~F}_{\text {sol }}$ & This study \\
\hline $\mathrm{MtrF}_{\text {sol }} \Delta 22-182$ & $\mathrm{Kan}^{\mathrm{R}}, \mathrm{P}_{\text {Ara }}, m t r F_{\text {sol }} \Delta 22-182$ & This study \\
\hline $\mathrm{MtrF}_{\mathrm{sol}} \Delta 22-182 \_\Delta 322-460$ & $\mathrm{Kan}^{\mathrm{R}}, \mathrm{P}_{\text {Ara }}, m t r F_{\text {sol }} \Delta 22-182 \_\Delta 322-460$ & This study \\
\hline $\operatorname{MtrF}_{\text {sol }} \Delta 22-182 \_\Delta 322-460 \_$Linker1 & $\mathrm{Kan}^{\mathrm{R}}, \mathrm{P}_{\text {Ara, }}, m$ trF $F_{\text {sol }} \Delta 22-182 \_\Delta 322-460 \_322::$ Linker $1: .460$ & This study \\
\hline 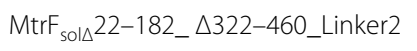 & $\mathrm{Kan}^{\mathrm{R}}, \mathrm{P}_{\text {Ara }}, m t r F_{\text {sol }} \Delta 22-182 \_\Delta 322-460 \_322::$ Linker2::460 & This study \\
\hline Cs & $\mathrm{Kan}^{\mathrm{R}}, \mathrm{P}_{\mathrm{Ara}}$ celstrep & This study \\
\hline Cs-MtrF sol & $\mathrm{Kan}^{\mathrm{R}}, \mathrm{P}_{\text {Ara }}$ celstrep_mtrF $F_{\text {sol }}$ & This study \\
\hline Cs-MtrF ${ }_{\text {sol }} \Delta 22-182$ & $\mathrm{Kan}^{\mathrm{R}}, \mathrm{P}_{\mathrm{Ara}^{\prime}}$ celstrep-mtrF $F_{\text {sol }} \Delta 22-182$ & This study \\
\hline $\mathrm{MtrF}_{\mathrm{sol}}-\mathrm{Cs}$ & $\mathrm{Kan}^{\mathrm{R}}, \mathrm{P}_{\mathrm{Ara}}, m$ trF $\mathrm{sol}_{\text {sol-celstrep }}$ & This study \\
\hline
\end{tabular}

All strains are based on S. oneidensis wild type. Different versions of outer membrane cytochrome genes and fusions with the celstrep gene were introduced using pBAD plasmids

An N-terminal strep tag for immunodetection of the secreted proteins via western blot was added to the sequence of primer 2 and 4 . A signal sequence (originating from the E. coli protein OmpA) for Sec-dependent secretion into the periplasm was amplified with primers 5 and 6 [29]. Primers of both fragments contain overlaps homologous to the vector and the corresponding fragments and were ligated into pBAD202. The resulting plasmids were named $\mathrm{pBAD} \_m t r F_{\text {sol }}$ and $\mathrm{pBAD} \_o m c A_{\text {sol }}$, respectively.

\section{Construction of different $\mathrm{MtrF}_{\text {sol }}$ strains}

For deletion of base pairs 22 to 182, primer P7 was used as a forward primer to amplify a truncated version of $m t r F$ with an overlap to the $o m p A$ fragment, whereas P2 served as reverse primer. OmpA fragment was amplified as described above. Both fragments were ligated into pBAD202. The resulting plasmid variant was named pBADmtrF $F_{\text {sol }} \Delta 22-182$.

pBAD $m t r F_{\text {sol }} \Delta 22-182$ served as template for the construction of the two further variants: $m t r F_{\text {sol }} \Delta 22-182 \_\Delta 322-460 \_L i n k e r 1$ and $m t r F-$ sol $\Delta 22-182 \_\Delta 322-460 \_L i n k e r 2$. Both were amplified via inverse PCR using primers P8 and P9 (Linker 1) or P10 and P11 (Linker 2) to add flexible linker sequences between AA321 and AA461.

\section{Construction of celstrep cellulase containing plasmids}

The sequence of the cellulase gene celstrep was published by Amore et al. [2] and is cataloged by EMBL database number HE862416. Since the previously designed plasmids contained the ompA-leader sequence, the endogenous Sec-export signal of celstrep was redundant and omitted for further gene design. Celstrep was coupled to $m t r F_{\text {sol }}$ variants to create recombinant fusion proteins. To ensure correct folding and function as well as to prevent steric interference of the two fusion protein components, their respective DNA sequences were separated by a short helical and therefore rigid spacer. This spacer descends from the Centre for Integrative Bioinformatics of the Vrije Universiteit Amsterdam and is cataloged by PDB number 19hc (Additional file 2: Table S2). The celstrep sequence was codon-optimized for $S$. oneidensis MR-1 via Java Codon Adaptation Tool (JCat) and provided by Life Technologies (Thermo Fischer, Germany) as a GeneArt ${ }^{\mathrm{TM}}$ Strings $^{\mathrm{TM}}$ DNA fragment (Additional file 3: Figure S1). For C-terminal fusion into $\mathrm{pBAD} \_m t r F_{s o l}$, the synthesized sequence contained regions homologous to the plasmid. pBAD_mtrF $F_{\text {sol }}$ was linearized with BstXI and integration of celstrep string fragment was accomplished via isothermal assembly. The spacer sequence was integrated into the sequence of primer 13. The resulting plasmid was named pBAD_mtrF $F_{\text {sol }}$-cs. Construction of pBAD_mtrF $F_{s o l} \Delta 22-182-c s$ was performed analogously.

For $\mathrm{N}$-terminal fusions of celstrep to $m t r F$ variants, the ompA leader sequence was amplified using P5 and P6. Moreover, celstrep was amplified using P12 and P13, mtrF $F_{\text {sol }}$ was amplified using P14 and P2 and $m t r F_{\text {sol }} \Delta 22-182$ using P15 and P2. Primers P13, P14 and P15 contain additional DNA sequences for the integration of the spacer at the $\mathrm{N}$-terminus of $m t r F$ variants. The fragments were ligated into $\mathrm{pBAD}$ via isothermal assembly and the resulting plasmids were named pBAD_cs-mtrF $F_{s o l}$ and $\mathrm{pBAD} \_c s-m t r F_{s o l} \Delta 22-182$, respectively. 


\section{Construction of a strain expressing Celstrep cellulase without coupling to MtrF $_{\text {sol }}$}

The celstrep gene sequence was amplified in a PCR reaction using P16 and P17 as primers and pBAD_cs-mtrF $F_{\text {sol }}$ as DNA template. The resulting fragment contained an $\mathrm{N}$-terminal ompA region and a C-terminal Strep-Tag ${ }^{\circledR}$ sequence. This DNA fragment was ligated into $\mathrm{pBAD}$ vector as described before.

\section{Protein enrichment, preparation of periplasmic fractions, SDS-PAGE and Western blotting}

Soluble proteins from culture supernatant were concentrated using Amicon ${ }^{\circledR}$ Ultra-15 Centrifugal Filter Units (Merck-Millipore, Germany) with an exclusion volume of $3 \mathrm{kDa}$. Cells were harvested at an $\mathrm{OD}_{600}$ of 0.4 and the supernatant was sterile-filtered with a $0.2 \mu \mathrm{m}$ filter. $50 \mathrm{ml}$ of the supernatant were concentrated to $500 \mu \mathrm{l}$ using centrifugal filter units at $3220 \times g$ and $4{ }^{\circ} \mathrm{C}$. Periplasmic protein fractions were isolated as described [10,31]. Protein concentrations were quantified by the method of Bradford [6], using bovine serum albumin as standard. Protein samples were separated on polyacrylamide gels [24] and the expression of the cytochromes was monitored via SDS-PAGE coupled with a heme-linked peroxidase stain [37]. Proteins containing a C-terminal Strep-Tag ${ }^{\circledR}$ were detected on a Western blot using primary strep-tag antibodies (Qiagen, Germany) and secondary mouse antibodies labeled with alkaline phosphatase (Sigma-Aldrich, Germany). Signal detection was conducted using the AP conjugate detection kit (BioRad, Germany).

\section{Cellulase activity assay}

Relative cellulase activity was assessed in triplicates by the method of Xiao et al. [40]. Commercially available cellulase ( 0.1 to 10 units $\mathrm{ml}^{-1}$ ) from Aspergillus niger was used to develop a standard curve.

\section{Results}

\section{MtrF is a suitable exporter for protein secretion}

The aim of this study was to establish outer membrane cytochromes of $S$. oneidensis as transporters for export of proteins into the medium using the type II secretion pathway. Outer membrane cytochromes are attached to the outer membrane with a lipid anchor, which is connected to the protein backbone at an N-terminal cysteine residue that is part of the so-called lipobox recognition sequence. It was speculated that deletion of this lipobox sequence leads to a secretion of the truncated cytochrome into the medium [27]. Previous work revealed that of the five putative outer membrane cytochromes encoded in the genome of S. oneidensis only three (OmcA, MtrC and MtrF) are exposed to the cell surface [8] and are consequently potential targets for the development of a protein exporter. Still, overexpression of MtrC seems to have a more pronounced toxic effect compared to MtrF [20]. Therefore, in a first step we compared the export efficiency of soluble versions of OmcA $\left(\mathrm{OmcA}_{\text {sol }}\right)$ and $\mathrm{MtrF}\left(\mathrm{MtrF}_{\text {sol }}\right)$ that lack the C-terminal lipobox sequences (amino acid deletions MtrF: $\Delta 1-22$; OmcA: $\Delta 1-32$ ). The corresponding genes were expressed in S. oneidensis wild type during anaerobic growth with lactate as electron donor and fumarate as electron acceptor and equal volumes of supernatant were analyzed for their heme signal. Anoxic conditions were used to assure identical concentration and activity of the heme maturation machinery. Both proteins hold the same number of heme centers, which is why the heme staining signals can be applied to compare the amount of exported protein. As is depicted in Fig. 1a, the concentrated supernatant of a soluble MtrF expressing culture reveals a more prominent red color and a corresponding higher signal intensity on a SDS-PAGE coupled with a heme-linked peroxidase stain compared to the identically treated samples of the wild type and the $\mathrm{OmcA}_{\text {sol }}$ expressing strain (Fig. 1b).

Moreover, when we screened for potential inhibitory effects of the overexpression by comparing the growth constants under different inductor concentrations, we observed that $m t r F_{\text {sol }}$ expression had a significantly lower impact on growth compared to $o m c A_{\text {sol }}$ (Fig. 2). Since $\mathrm{MtrF}_{\text {sol }}$ seems to be exported more efficiently and with less inhibitory side effects compared to $\mathrm{OmcA}_{\text {sol }}$, all further experiments were conducted with $\mathrm{MtrF}_{\text {sol }}$.

\section{Determination of the MtrF export signal}

The protein structure defining T2SS substrates like MtrF for translocation through the outer membrane is unknown. Our aim was to use a stepwise deletion in the $\mathrm{MtrF}_{\text {sol }}$ amino acid sequence to find the part of the primary structure that is relevant for recognition by the T2SS. This would increase the molecular weight ratio of cargo to exporter in the envisioned fusion proteins between $\mathrm{MtrF}_{\text {sol }}$ and an attached protein. The deletion strategy was developed using information from the 3D crystal structure of MtrF (PDB ID 3PMQ [12]). MtrF is composed of four domains (D1-D4). Two of these domains form a central protein core (D2 and D4) and are flanked by domains D1 and D3 (Fig. 3).

Partial deletions of peptide chain segments often have a far-reaching impact on protein structure and stability. Moreover, the alteration of heme coordination was shown to influence protein stability in multiheme proteins $[1,9,16,33]$. Hence, we developed $\mathrm{MtrF}_{\text {sol }}$ deletion variants that are truncated as far as possible, but are not affected in heme coordination. Most of the interaction of the heme groups happen within the core 


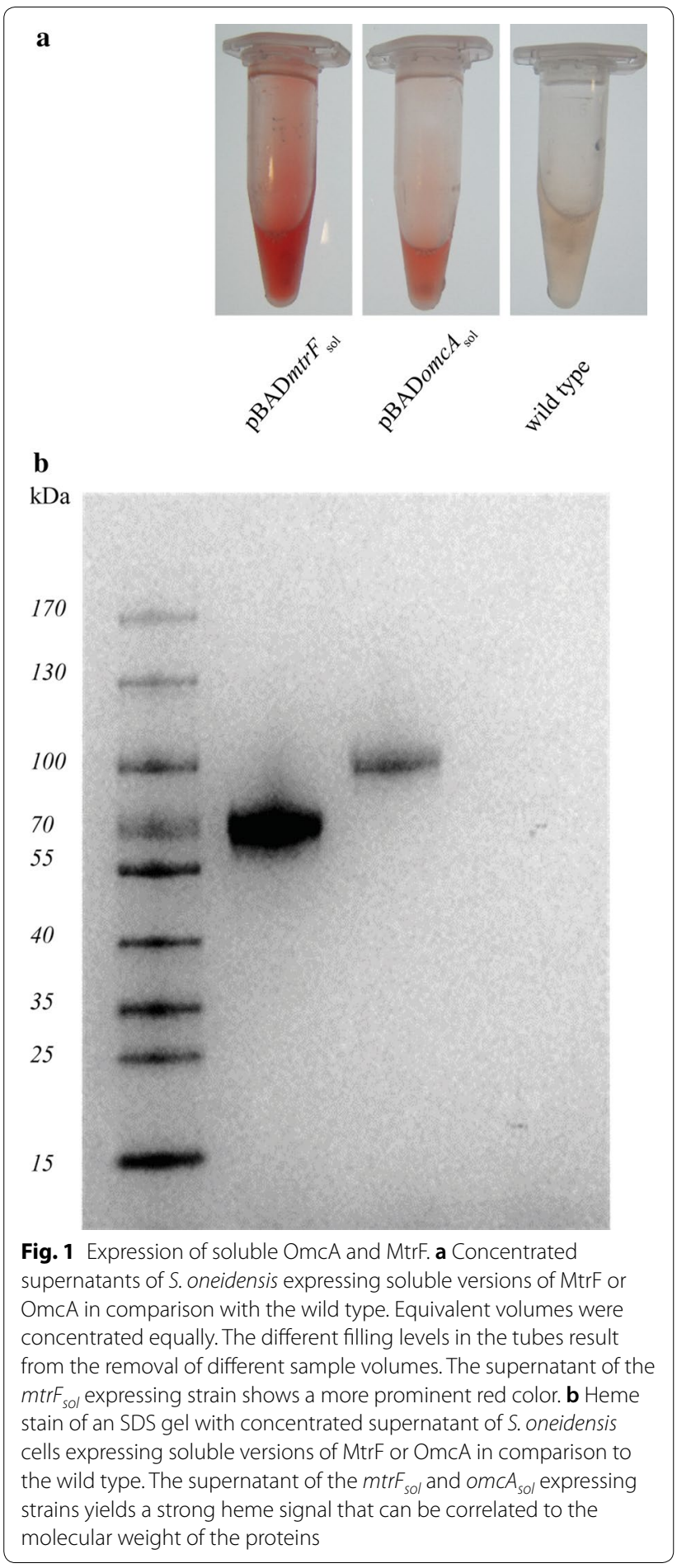

domains D2 and D4. However, there are three exceptions, namely the amino acids 186, 464 and 465 that interact with hemes in the domains D1 and D3. Thus, D1 and D3 cannot be completely deleted without affecting the heme bonds. Initially, the first 182 amino acid residues (major part of D1) were deleted leading to strain $\mathrm{MtrF}_{\mathrm{sol}} \Delta 22-182$. In addition to the removal of the 182 N-terminal amino acids, deletion of amino acid 322460 (major part of D3) was conducted, resulting in strain $\mathrm{MtrF}_{\text {sol }} \Delta 22-182 \_\Delta 322-460$. With these deletions it was possible to remove most of the peptide sequence without affecting the heme coordination sites of the remaining core domains. Since direct fusion of peptide fragments after removal of interjacent amino acid sequences often leads to a massive change in protein conformation, the gap between $\mathrm{D} 2$ and $\mathrm{D} 4$ was bridged with a small flexible peptide linker to maintain the original orientation and conformation of the core domains. In the original MtrF protein structure, the distance between amino acids 321 and 461 is roughly $25.5 \AA$. In general, flexible protein linkers often consist of glycine (G) and serine (S) residues, forming modules of (GGGGS) peptides [3, 11]. In the case of $\mathrm{MtrF}_{\mathrm{so}}$, a dimer (GGGGS) ${ }_{2}$ or a trimer (GGGGS) of this module named linker 1 or 2 , respectively was used to bridge the gap between D2 and D4. These two peptide linkers were inserted between AA321 and AA461 in the deletion strain $\mathrm{MtrF}_{\text {sol }} \Delta 22-182 \_\Delta 322-460$, resulting in two strains: $\mathrm{MtrF}_{\text {sol }} \Delta 22-182 \_\Delta 322-460 \_$Linker1 which has a dimer of the linker sequence inserted, and $\mathrm{MtrF}_{\text {sol }} \Delta 22-182 \_\Delta 322-460 \_$Linker2 having a trimer of the linker sequence inserted (Fig. 4). Of note, the models depicted in Fig. 4 are based on the assumption that the individual structure of the remaining domains does not change after deletion of other domains, which is surely a simplification of the reality. Hence, Fig. 4 should be used as a scheme helping to understand the individual deletions and rearrangements of the primary protein structure. Further details on the DNA sequences of the linkers used in this study are described in Additional file 2: Table S2.

All constructs were expressed under identical conditions in S. oneidensis wild type. After the cells reached $\mathrm{OD}_{600} 0.4$ the cells were harvested. The supernatant was concentrated to identical volumes and the periplasm of the cells was isolated. Western blotting analysis of the protein fractions obtained from the different strains using the N-terminal Strep-tag epitope revealed synthesis as well as secretion of $\mathrm{MtrF}_{\text {sol }}$ variants only for the $\mathrm{N}$-terminally truncated $\mathrm{MtrF}_{\text {sol }} \Delta 22-182$ (Fig. 5). Deletion of amino acids $322-460$ seems to lead to instable proteins since they are neither detectable in the periplasm nor in the supernatant.

\section{Outer membrane cytochromes as transporter for extracellular proteins}

The potential ability of $\mathrm{MtrF}_{\text {sol }}$ to transport other proteins into the medium was tested with the $\beta-1,4$ endoglucanase Celstrep from Streptomyces sp. [2]. This 


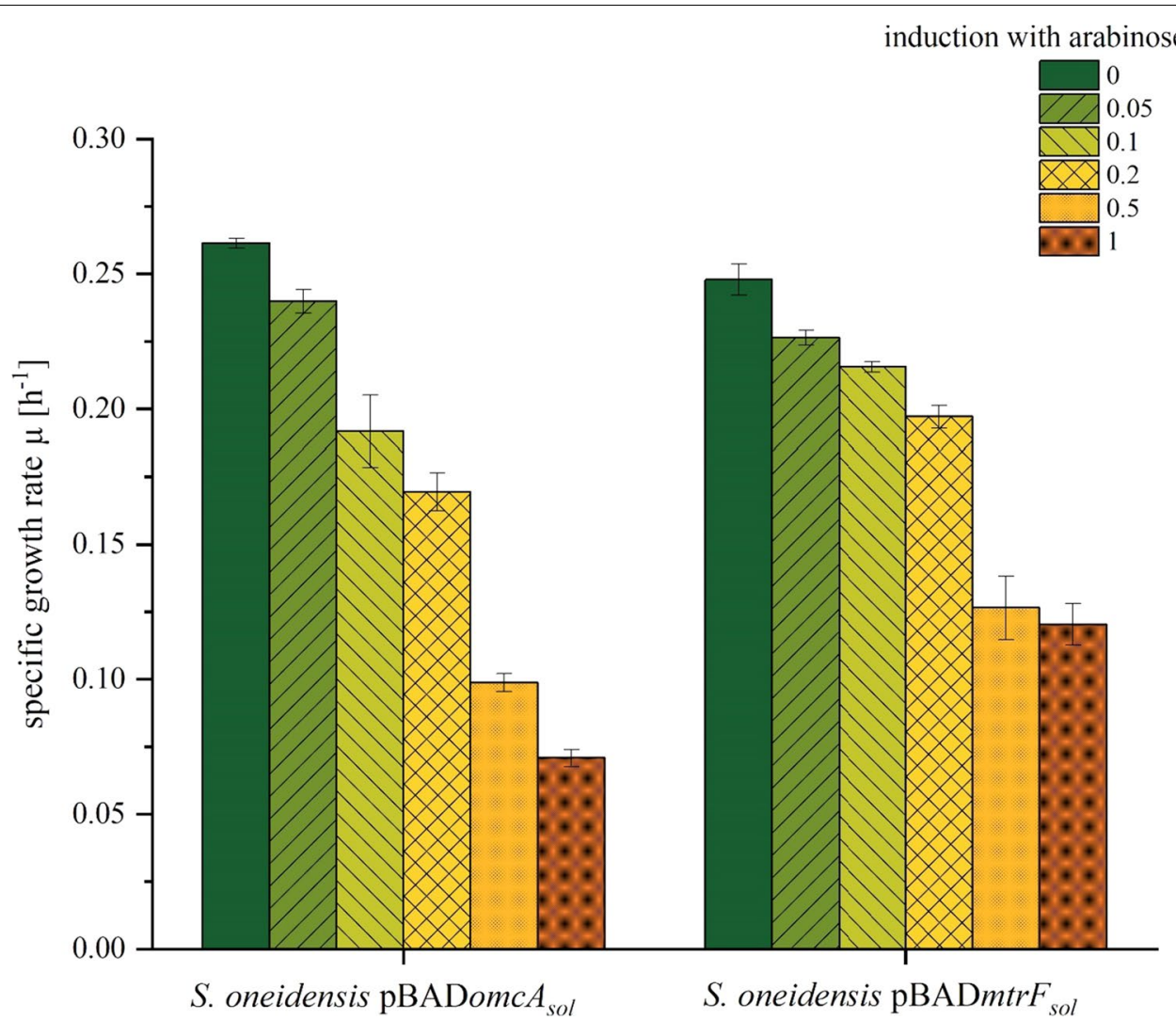

Fig. 2 Specific growth rates of S. oneidensis strains with different inducer concentrations. S. oneidensis cultures expressing soluble versions of OmcA and MtrF, respectively, were induced with different concentrations of arabinose. Cell growth was monitored for $12 \mathrm{~h}$ and the specific growth rate was calculated. Error bars represent the standard deviations from means of samples taken in independent triplicates

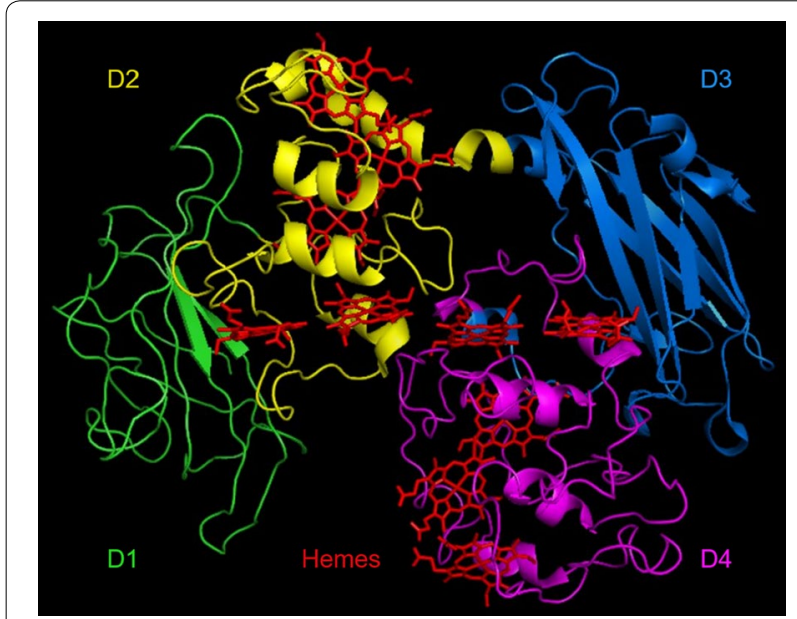

Fig. 3 Crystal structure of MtrF. MtrF is composed of the four domains D1 (green), D2 (yellow), D3 (blue) and D4 (purple). The core domains D2 and D4 carry the ten heme groups (red) and are flanked by D1 and D3. 3D protein structures were imaged with the molecular visualization system PyMOL protein was chosen due to its potential applicability and because of the possibility to easily quantify the activity of the protein. Hence, the celstrep gene was coupled to the N-and C-terminus of $m t r F_{s o l}$ and $m t r F_{\text {sol }} \Delta 22-182$. A plasmid version containing the celstrep gene coupled to an N-terminal export sequence for Sec-dependent transport into the periplasm served as negative control, as this protein will not be exported from the periplasm by the T2SS. For immuno-detection, all fusion protein constructs contained a strep-tag sequence as epitope on the C-terminus.

As depicted in Fig. 6, the fusion proteins can be detected in the supernatant and in the periplasm in differing amounts. In agreement with the secretion experiments conducted with soluble versions of MtrF alone, we see that the full-length version seems to be exported more efficiently when fused with the cellulase, as the amount of residual fusion protein in the periplasm is lower compared to the $\mathrm{MtrF}_{\text {sol }} \Delta 22-182$ versions. The Western blot also reveals the results of protein degradation by protein bands of lower molecular weight compared to the expected full-length proteins. C-terminal 


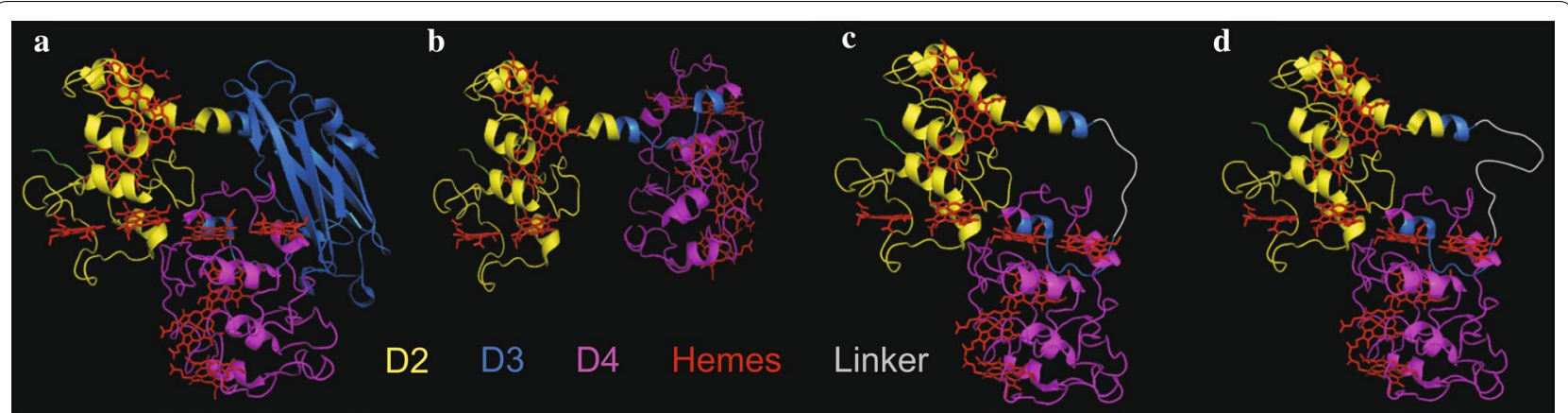

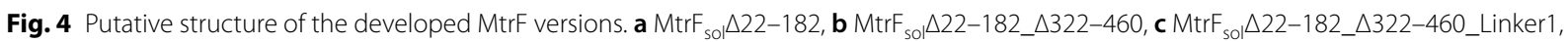

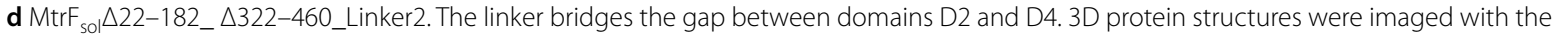
molecular visualization system PyMOL

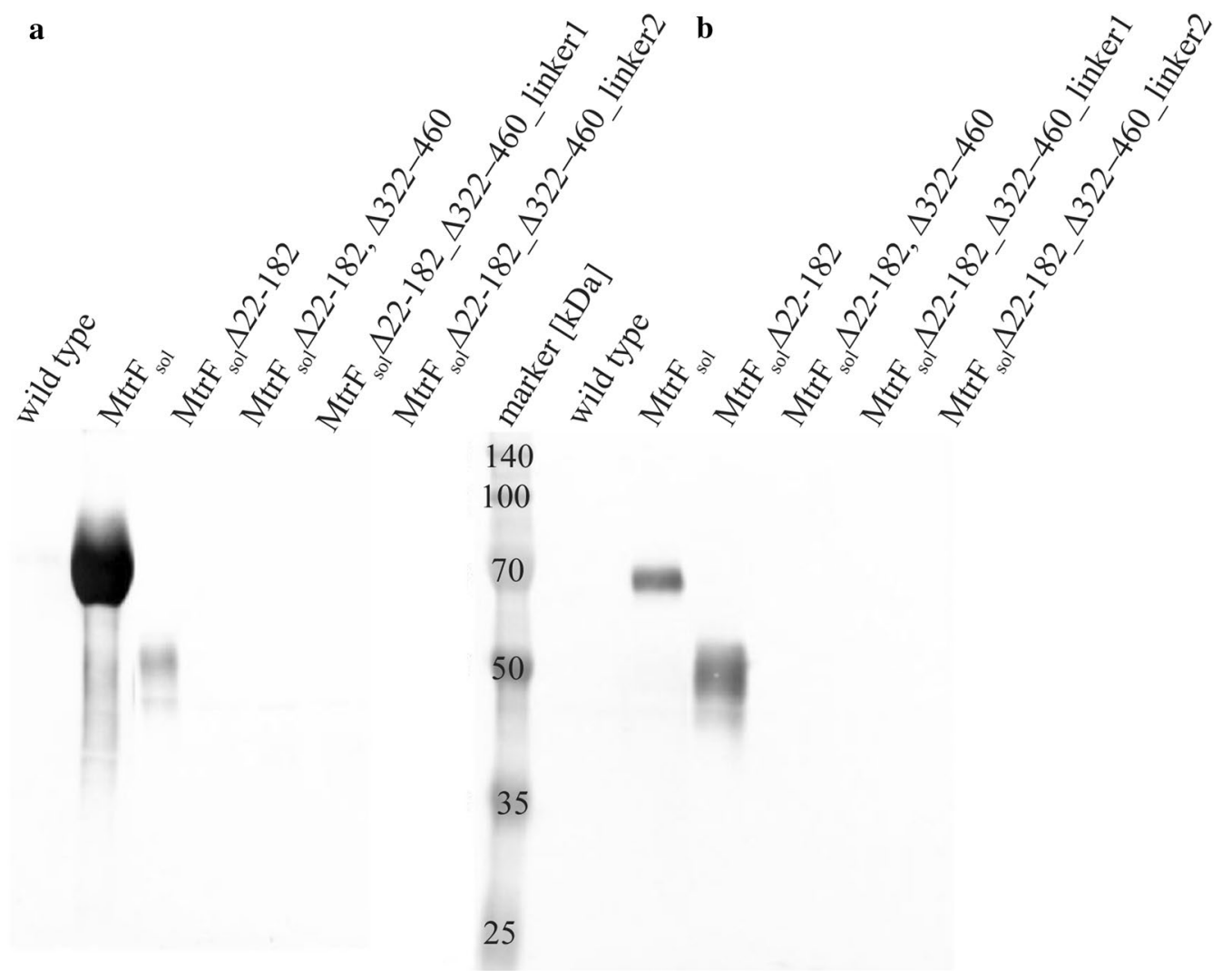

Fig. 5 Western blot of different MtrF variants. a Concentrated supernatant, $\mathbf{b}$ periplasmic fraction of the MtrF versions. Only in the MtrF ${ }_{\text {sol }}$ and the $\mathrm{MtrF}_{\text {sol }} \Delta 22-182$ strains a signal can be detected in the supernatant and the periplasm, respectively

fusions seem to be less efficiently exported and less stable compared to the $\mathrm{N}$-terminal counterparts. The control experiment with the Celstrep gene containing only a leader for the export into the periplasm reveals only a faint band in the supernatant which might be a result of cell lysis.

An activity assay that measures the relative hydrolysis of carboxymethylcellulose (CMC) based on a method described by Xiao et al. [40] was conducted to assess the functionality of the exported proteins and to functionally compare the secretion efficiency [40]. Supernatants of $S$. oneidensis wild type cells, of cells expressing $m t r F_{s o l}$, and of wild type cells expressing $\mathrm{N}$-terminal celstrep fusions were used for the activity analysis. Of note, only the $\mathrm{N}$-terminal fusions were used as the analysis revealed a higher amount of protein in the supernatant compared to 


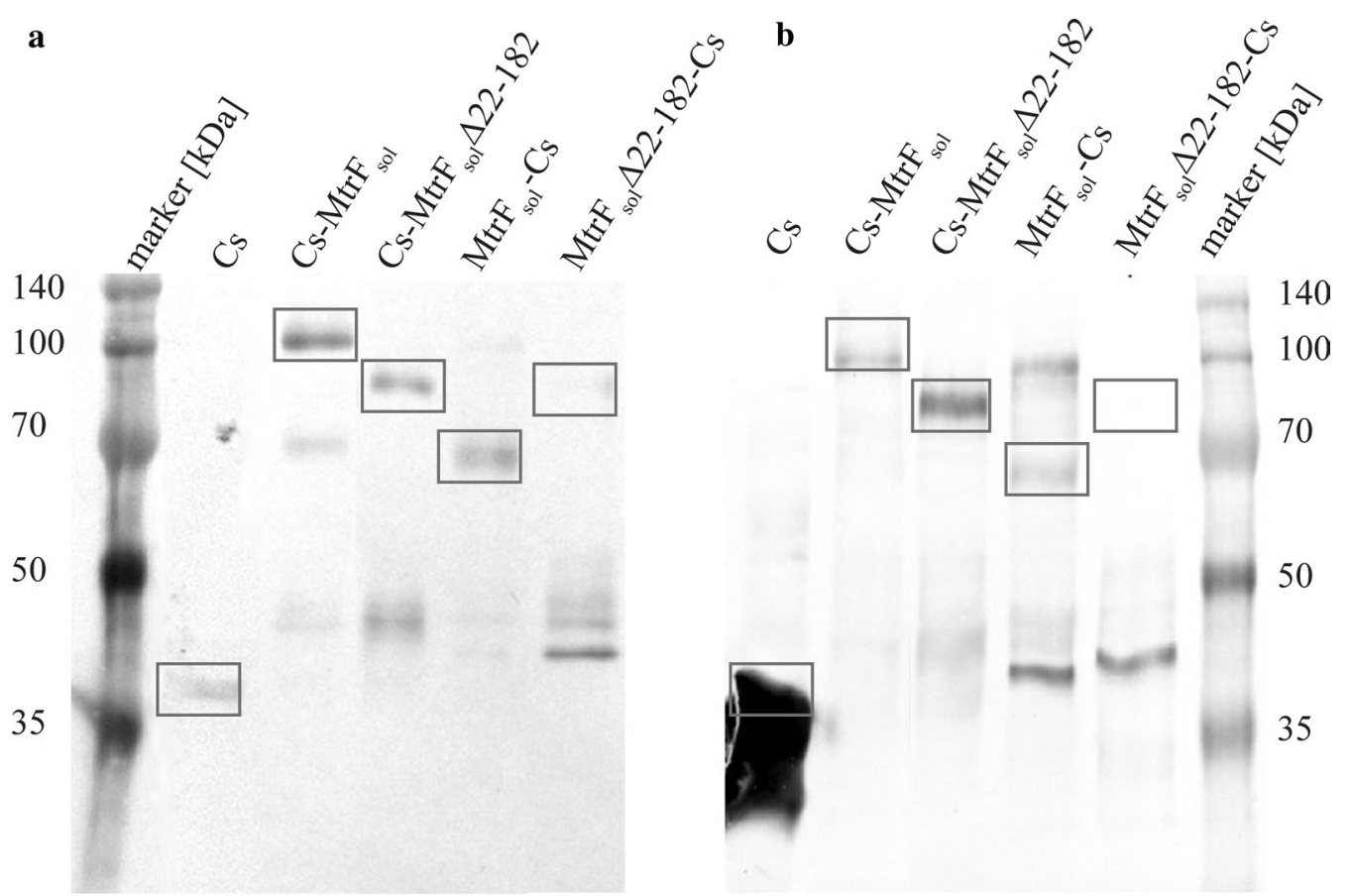

Fig. 6 Expression of MtrF-Celstrep (MtrF-Cs) fusion proteins. Square frames indicate the size of the respective labeled proteins. Part a displays the concentrated supernatant and $\mathbf{b}$ the periplasmic fraction. Uncoupled cellulase can be barely found in the supernatant but there is a high amount of cellulase detected in the periplasm. The fusion proteins with the cellulase fused to the $\mathrm{N}$-terminus can both be found in the supernatant and the periplasm. Full length fusion proteins with the cellulase attached to the C-terminus are barely detectable in the supernatant

the C-terminal fusions. Supernatants were concentrated equally and their cellulase activity was measured using a calibration curve derived with a commercially available cellulase. The activity was normalized to the original volume of the supernatant. No activity was detectable in wild type and $m t r F_{\text {sol }}$ expressing cells. The activity in the supernatant of $c s-m t r F_{s o l}$ expressing cells contained a cellulase activity of $10.8( \pm 2.2) \mathrm{U} / \mathrm{ml}$. The activity in the supernatant of $c s-m t r F_{\text {sol }} \Delta 22-182$ expressing cells was insignificantly lower. The supernatant of cells expressing the celstrep protein alone contained only $19 \%$ of the activity of the $c s-M t r F_{\text {sol }}$ supernatant (Fig. 7).

\section{Discussion}

Shewanella oneidensis is capable of extracellular respiration and in this process dependent on secretion of outer membrane cytochromes across the outer membrane via the T2SS. So far, it is unknown which areas of the T2SS substrates are responsible for the export information and enable the interaction with the T2SS components, and also the substrates do not show clear sequence homologies. Besides the scientific aspect to identify the secretion signal of the T2SS, there is also great interest from an applied point of view in the investigation of this export structure.

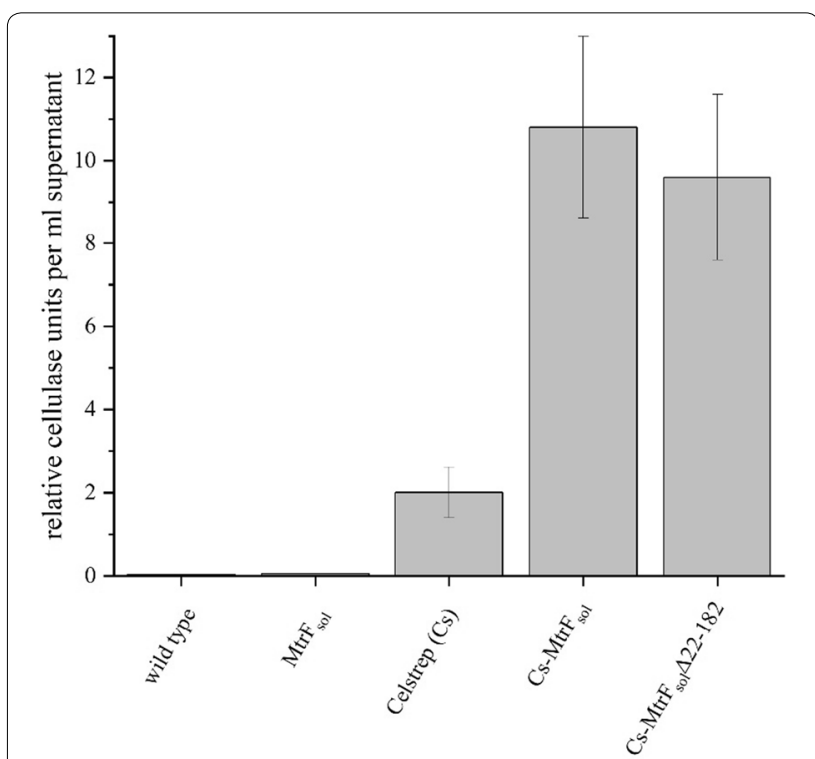

Fig. 7 Cellulase activity of different MtrF fusion proteins. The negative controls (supernatants from wild type and $\mathrm{MtrF}_{\text {sol }}$ expressing cells) did not reveal any activity. The supernatant from cells expressing the cellulase only with a Sec-leader sequence for export in the periplasm (Cs) shows a rather low activity, whereas MtrF-coupled constructs are up to 3-5 times more active

This study revealed that it is possible to secrete 
truncated versions of outer membrane cytochromes into the culture supernatant and that these proteins can be used as transporter for the export of heterologously produced proteins. Interestingly, no secretion was detectable after any further region of the MtrF protein besides amino acids 22-182 was deleted. All further deletions seem to be unstable as they could neither be detected in the periplasm nor in the culture supernatant. Domain D1 was identified as dispensable for a stable protein, whereas domain D3 is essential. The protein structure of this indispensable segment contains six antiparallel $B$-sheet structures. Antiparallel $ß$-sheets are conserved among many proteins that are transported via the T2SS [36]. In MtrF, the $B$-barrel structure is presumably responsible for flavin binding [12]. Our study suggests that the B-sheets in domain D3 are of such high importance for the protein that removal of these regions leads to protein degradation.

Moreover, the results from experiments with two different versions of MtrF-CelStrep fusion proteins suggest that especially the $\mathrm{C}$-terminus of the protein is relevant for protein export. A C-terminal fusion is exported to the culture supernatant barely or only to a very minor percentage, whereas an $\mathrm{N}$-terminal fusion protein is secreted efficiently.

The production and the export of heterologously expressed proteins comes with a certain metabolic burden as a significant portion of cellular resources has to be allocated to this process [39]. Hence, there will be a strong selective force towards mutations since this cellular task is not connected with a physiological benefit. However, we hypothesize that the here-described tool for protein export could not only be used for a variety of cargo proteins but that it could also lead to a more stable long-term production and even to an autonomous selfadvancing system. This hypothesis could be proven in an S. oneidensis deletion mutant that is devoid of any native outer membrane $c$-type cytochrome gene and instead capable of expressing a fusion protein consisting of a soluble outer membrane cytochrome and a cargo protein. Under conditions in which extracellular respiration is required (for example in a bioelectrochemical system), the strain has to express the soluble outer membrane cytochrome in order to thrive on the extracellular electron acceptor (the anode) and by this will benefit from cytochrome production. Furthermore, the strain will even take advantage from an evolutionary drift towards more efficient protein production and export. This selfadvancing process in combination with the simultaneous production of the cargo protein could lead to a significantly enhanced protein production.

Besides the approximate localization of the secretion motif the functional integration of a rather rigid linker between the transporter and the cargo protein gives reason to assume that addition of a site-specific protease cleavage domain will be also implementable and by this it will be possible to gain the desired protein without fusion to the outer membrane cytochrome.

\section{Conclusions}

This study demonstrates that a deletion of the lipid anchor of the outer membrane cytochromes OmcA and MtrF of the proteobacterium S. oneidensis leads to secretion of the truncated proteins into the culture supernatant via the T2SS. Further deletions reduced the size of secreted MtrF by 160 amino acids and revealed that for effective protein secretion the C-terminus is of particular relevance. Furthermore, a fusion of MtrF and a cellulase was secreted efficiently and gives evidence that the heredescribed tool for protein export can be used for a variety of cargo proteins. In this way, biotechnological applications such as production of proteins with cofactors can be optimized in terms of quality and efficiency.

\section{Supplementary information}

Supplementary information accompanies this paper at https://doi. org/10.1186/s12934-019-1270-2.

Additional file 1: Table S1. Primer used in this study.

Additional file 2: Table S2. Sec leader, linker and spacer sequences used in this study.

Additional file 3: Figure S1. Celstrep DNA string. The celstrep gene was codon-optimized for S. oneidensis MR-1 and a 42 bp DNA spacer was added upstream of the gene. The sequence is flanked by homologous regions of the PBAD_mtrFso/ plasmid, including the final base pairs of $m$ trF as well as Strep-Tag sequence ( $\mathrm{N}$-terminally) and downstream region of the pBAD vector (C-terminally). Additionally, the DNA string contains a Sacl restriction site at the beginning and a Xbal site at the end of the sequence.

\section{Authors' contributions}

All listed authors have approved the manuscript before submission, including the names and order of authors All authors will receive the submission and all substantive correspondence with editors, as well as the full reviews. All data, figures and materials comply with the transparency and reproducibility standards of both the field and journal. All authors read and approved the final manuscript.

\section{Funding}

This project was funded by the state of Baden-Wuerttemberg (support code 7533-10-5-191).

\section{Availability of data and materials}

All data generated or analysed during this study are included in this published article and its supplementary information files or the datasets used and/ or analysed during the current study are available from the corresponding author on reasonable request.

Ethics approval and consent to participate Not applicable. 


\section{Consent for publication \\ Not applicable.}

\section{Competing interests}

The authors declare that they have no competing interests.

\section{Author details}

${ }^{1}$ Department of Molecular Microbiology and Bioenergetics, Goethe University, Frankfurt, Germany. ${ }^{2}$ Department of Applied Biology, Institute for Applied Biosciences, Karlsruhe Institute of Technology (KIT), Karlsruhe, Germany. ${ }^{3}$ Institute for Biological Interfaces, Karlsruhe Institute of Technology (KIT), Eggenstein-Leopoldshafen, Germany.

Received: 21 October 2019 Accepted: 13 December 2019 Published online: 23 December 2019

\section{References}

1. Allen JWA, Tomlinson EJ, Hong L, Ferguson SJ. The Escherichia coli cytochrome c maturation (Ccm) system does not detectably attach heme to single cysteine variants of an apocytochrome c. J Biol Chem. 2002;277:33559-63.

2. Amore A, Pepe O, Ventorino V, Birolo L, Giangrande C, Faraco V. Cloning and recombinant expression of a cellulase from the cellulolytic strain Streptomyces sp G12 isolated from compost. Microb Cell Fact. 2012;11:164.

3. Argos P. An investigation of oligopeptides linking domains in protein tertiary structures and possible candidates for general gene fusion. J Mol Biol. 1990;211:943-58.

4. Beblawy S, Bursac T, Paquete C, Louro R, Clarke TA, Gescher J. Extracellular reduction of solid electron acceptors by Shewanella oneidensis. Mol Microbiol. 2018:109:571-83.

5. Beliaev AS, Saffarini DA, McLaughlin JL, Hunnicutt D. MtrC, an outer membrane decahaem c cytochrome required for metal reduction in Shewanella putrefaciens MR-1. Mol Microbiol. 2001;39:722-30.

6. Bradford MM. A rapid and sensitive method for the quantitation of microgram quantities of protein utilizing the principle of protein-dye binding. Anal Biochem. 1976;72:248-54.

7. Bretschger O, Obraztsova A, Sturm CA, Chang IS, Gorby YA, Reed SB, et al. Regulation of dissimilatory Fe(III) reduction activity in Shewanella putrefaciens. Appl Environ Microbiol. 2007;56:2811-7.

8. Bücking C, Popp F, Kerzenmacher S, Gescher J. Involvement and specificity of Shewanella oneidensis outer membrane cytochromes in the reduction of soluble and solid-phase terminal electron acceptors. FEMS Microbiol Lett. 2010;306:144-51.

9. Cartron ML, Roldán MD, Ferguson SJ, Berks BC, Richardson DJ. Identification of two domains and distal histidine ligands to the four haems in the bacterial c-type cytochrome NapC; the prototype connector between quinol/ quinone and periplasmic oxido-reductases. Biochem J. 2002;368:425-32.

10. Cerny G, Teuber M. Differential release of periplasmic versus cytoplasmic enzymes from Escherichia coli B by polymyxin B. Arch Mikrobiol. 1971;78:166-79.

11. Chen $X$, Zaro JL, Shen W-C. Fusion protein linkers: property, design and functionality. Adv Drug Deliv Rev. 2013;65:1357-69.

12. Clarke TA, Edwards MJ, Gates AJ, Hall A, White GF, Bradley J, et al. Structure of a bacterial cell surface decaheme electron conduit. Proc Natl Acad Sci U S A. 2011;108(23):9384-9. https://doi.org/10.1073/pnas.1017200108.

13. Costa NL, Clarke TA, Philipp L-A, Gescher J, Louro RO, Paquete CM. Electron transfer process in microbial electrochemical technologies: the role of cellsurface exposed conductive proteins. Bioresour Technol. 2018:255:308-17.

14. Coursolle D, Baron DB, Bond DR, Gralnick JA. The Mtr respiratory pathway is essential for reducing flavins and electrodes in Shewanella oneidensis. J Bacteriol. 2010;192:467-74.

15. DiChristina TJ, Moore CM, Haller CA. Dissimilatory Fe(III) and Mn(IV) reduction by Shewanella putrefaciens requires ferE, a homolog of the pulE ( $g s p E$ ) type II protein secretion gene. J Bacteriol. 2002;184:142-51.

16. Dolla A, Florens L, Bianco P, Haladjian J, Voordouw G, Forest E, et al. Characterization and oxidoreduction properties of cytochrome c3 after heme axial ligand replacements. J Biol Chem. 1994;269:6340-6.

17. Gerlach RG, Hensel M. Protein secretion systems and adhesins: the molecular armory of gram-negative pathogens. Int J Med Microbiol. 2007:297:401-15.
18. Ghosh P. Process of protein transport by the type III secretion system. Microbiol Mol Biol Rev. 2004;68:771-95.

19. Gibson DG, Young L, Chuang RY, Venter JC, Hutchison CA 3rd, Smith HO. Enzymatic assembly of DNA molecules up to several hundred kilobases. Nat Methods. 2009;6(5):343-5. https://doi.org/10.1038/nmeth.1318.

20. Golitsch F, Bücking C, Gescher J. Proof of principle for an engineered microbial biosensor based on Shewanella oneidensis outer membrane protein complexes. Biosens Bioelectron. 2013;47:285-91.

21. Gu S, Rehman S, Wang X, Shevchik VE, Pickersgill RW. Structural and functional insights into the pilotin-secretin complex of the type II secretion system. PLoS Pathog. 2012;8:e1002531.

22. Jamur MC, Oliver C. Permeabilization of cell membranes. Methods in molecular biology. Clifton: Humana Press; 2010. p. 63-6.

23. Koster $M$, Bitter W, Tommassen J. Protein secretion mechanisms in gramnegative bacteria. Int J Med Microbiol. 2000;290:325-31.

24. Laemmli UK. Cleavage of structural proteins during the assembly of the head of bacteriophage T4. Nature. 1970;227:680-5.

25. Lutz $\mathrm{R}$, Bujard $\mathrm{H}$. Independent and tight regulation of transcriptional units in Escherichia coli via the LacR/O, the TetR/O and AraC/I1-12 regulatory elements. Nucleic Acids Res. 1997:25:1203-10.

26. Myers $\mathrm{CR}$, Nealson $\mathrm{KH}$. Bacterial manganese reduction and growth with manganese oxide as the sole electron acceptor. Science. 1988:240(4857):1319-21.

27. Myers CR, Myers JM. The outer membrane cytochromes of Shewanella oneidensis MR-1 are lipoproteins. Lett Appl Microbiol. 2004;39:466-70.

28. Parizad E, Parizad E, Pakzad I, Valizadeh A. A review of secretion systems in pathogenic and non-pathogenic bacteria. Biosci Biotechnol Res Asia. 2016;13:135-45

29. Pechsrichuang P, Songsiriritthigul C, Haltrich D, Roytrakul S, Namvijtr P, Bonaparte N, Yamabhai M. OmpA signal peptide leads to heterogenous secretion of B. subtilis chitosanase enzyme from E. coli expression system. Springerplus. 2016;5:1200.

30. Pineau C, Guschinskaya N, Robert X, Gouet P, Ballut L, Shevchik VE. Substrate recognition by the bacterial type II secretion system: more than a simple interaction. Mol Microbiol. 2014;94:126-40.

31. Pitts KE, Dobbin PS, Reyes-Ramirez F, Thomson AJ, Richardson DJ, Seward HE. Characterization of the Shewanella oneidensis MR-1 Decaheme Cytochrome MtrA. J Biol Chem. 2003:278:27758-65.

32. Possot OM, Gérard-Vincent M, Pugsley AP. Membrane association and multimerization of secreton component pulC.J Bacteriol. 1999:181:4004-11.

33. Reyes C, Qian F, Zhang A, Bondarev S, Welch A, Thelen MP, Saltikov CW. Characterization of Axial and Proximal Histidine Mutations of the Decaheme Cytochrome MtrA from Shewanella sp. Strain ANA-3 and Implications for the Electron Transport System. J Bacteriol. 2012;194:5840-7.

34. Richter K, Schicklberger M, Gescher J. Dissimilatory reduction of extracellular electron acceptors in anaerobic respiration. Appl Environ Microbiol. 2012;78:913-21.

35. Rondelet A, Condemine G. Type II secretion: the substrates that won't go away. Res Microbiol. 2013:164:556-61.

36. Sandkvist M. Biology of type II secretion. Mol Microbiol. 2001;40:271-83.

37. Thomas PE, Ryan D, Levin W. An improved staining procedure for the detection of the peroxidase activity of cytochrome P-450 on sodium dodecyl sulfate polyacrylamide gels. Anal Biochem. 1976:75:168-76.

38. Tosi T, Nickerson NN, Mollica L, Jensen MR, Blackledge M, Baron B, et al. Pilotin-secretin recognition in the type II secretion system of Klebsiella oxytoca. Mol Microbiol. 2011;82:1422-32.

39. Wu G, Yan Q, Jones JA, Tang YJ, Fong SS, Koffas MAG. Metabolic burden: cornerstones in synthetic biology and metabolic engineering applications. Trends Biotechnol. 2016;34:652-64.

40. Xiao Z, Storms R, Tsang A. Microplate-based carboxymethylcellulose assay for endoglucanase activity. Anal Biochem. 2005;342:176-8.

41. Zhang G, Brokx S, Weiner JH. Extracellular accumulation of recombinant proteins fused to the carrier protein YebF in Escherichia coli. Nat Biotechnol. 2006:24:100-4.

\section{Publisher's Note}

Springer Nature remains neutral with regard to jurisdictional claims in published maps and institutional affiliations. 